Western University

Scholarship@Western

$5-29-2009$

\title{
Rural Youth, Reading and Libraries: Fostering a Place Ballet
}

Paulette Rothbauer

Western University, prothba2@uwo.ca

Follow this and additional works at: https://ir.lib.uwo.ca/fimspres

Part of the Library and Information Science Commons

Citation of this paper:

Rothbauer, Paulette, "Rural Youth, Reading and Libraries: Fostering a Place Ballet" (2009). FIMS

Presentations. 55.

https://ir.lib.uwo.ca/fimspres/55 
Rural Youth, Reading

and Libraries: Fostering

a Place Ballet

CAIS/ACSI 200929 May 2009

Carleton University

Ottawa, Ontario

\section{Paulette Rothbauer}

Faculty of Information \& Media Studies

The University of Western Ontario 


\section{Literature Review}

Rural Library Services

(e.g., Wigg 1995; Johnson 2000; Conway 2005; Knight 2002; Vavrek 1995)

Cultural Geographies of Rural Youth

(e.g., Valentine \& Holloway 2001; Dunkley 2004; Philo 1992; Rye 2006; Lægran 2002; Leyshon 2002)

Library as Place

(e.g., Leckie \& Buschman 2007; Given \& Leckie 2003;

Leckie and Hopkins 2002) 


\section{The Research Questions}

What are the dimensions of rural and smalltown youth's engagement with print culture?

What is the place of the rural library in the context of reading habits of these youth? 


\section{Qualitative Research Methods}

\section{Sampling:}

Site and purposive sampling of participants

\section{Data Collection:}

Unobtrusive participant observation

Environmental scanning: access to print culture

Conversational interviews with youth

readers and nonreaders

27 participants (14 female, 13 male; no visible minorities; median age $=17$ years; all attended school)

Field notes

\section{Data analysis :}

Transcription of interview data

TAMS Analyzer 3.0 - software for qualitative data analysis

Open coding of all data; data immersion and reduction, thematic analysis 


\section{The Research Setting}

- A single rural municipality in Southwestern Ontario

- Population of 10,000 (mostly white, mostly Christian, large bluecollar workforce)

$3.7 \%$ males between $15-19$ years of age

$3.7 \%$ females between $15-19$ years of age

$40 \%$ of youth live in the only town

- One full service library, one small branch

- One high school, several churches, sporting arenas

- One Christian bookstore, no music stores, cinemas, internet cafes

- No dedicated teen only spaces

- Economic pillars of county are manufacturing, tourism and agriculture 


\section{Spatial Dimensions of Reading}

\section{Major Themes*}

1) Physical Proximity and Everyday Access to Reading Materials

2) Shifting Visibility of the Library

3) The Internet as a Default Place for Reading

4) Lack of Space in Time for Reading

* For more on themes, see article: Rothbauer, Paulette. "Exploring the Placelessness of Reading Among Older Teens in a Canadian Rural Municipality." The Library Quarterly, forthcoming October 2009. 


\section{Proximity and Everyday Access}

"Wherever I see it, l'll grab a copy"

(Tim, 16 yrs, "big fan" of reading books)

"I was just looking in my brother's books and I picked it out"

(Brent, 18 yrs, "not much" of a reader)

"We have a lot of books already so I just pick one that I like"

(William, 15 yrs, a light reader) 


\section{Shifting Visibility of Library}

Place to use computers

"I do recall the last time I was [at the library]. I think my computer broke, so I had to use the computer there" (Joe, 16, avid reader)

Place of childhood reading

"I used to [use the public library], but not anymore. I was younger - I used to read books" (Darren, 17 yrs., reads almost exclusively online)

'Negative' space defined by what the library does not offer

no downloading, no use of remote media, no linux manuals, no Christian fiction, "least accessible hours for anyone who is a student" 


\section{Internet as a Default Reading Site}

In their everyday lives, participants are..."already there" in front of the screen and "already there" online.

"I go on the internet like every night to read...kind of like a habit: every night, I go home, go to the computer, read stuff. Any time I find the time. Just whenever I walk in" (Darren, 17 yrs) 


\section{Lack of Space in Time for Reading}

- I wouldn't say hate to read, but I find I don't have a lot of time to actually read. A lot of time I read like newspapers and stuff like that [...] I also have a hard time finding books that I like [...] I do a lot of extracurricular activities, lot of volunteering. I play two sports - I play hockey and curling, I do that basically every night. [By the time I get home] I basically just do my homework. (Leah, 18 years old)

- I'd definitely be one of those people who don't like to read a lot. Like, l'd probably like to read more [...] l'll start books but I won't finish them. And I just don't know what it is, but [...] I just kind of forget about it. Like it's - like you want to read it but you don't find the time. (Daniel, 17 years old) 


\section{Placelessness of Reading}

Spatial isolation from rich print culture

- Few sites of access to reading materials = shallow field of print culture

- Little evidence of reading events, communities of readers

- The lone teen reader

- Reading choices based on availability, proximity, convenience

- Reading = utterly mundane experience, but not insignificant 


\section{And yet...}

Overwhelming evidence of habitual, daily enactment of reading practices...

Reading is happening everywhere, all the time, without notice or comment = mundane, takenfor-granted, essential feature of everyday life...

Is it possible to foster a sense of place for reading among youth? 


\section{"Place Choreography"}

Derek Seamon, phenomenological geographer, $A$ Geography of the Lifeworld: Movement, Rest and Encounter. NY: St. Martin's Press, 1979.

Shaun Moores, media scholar, Media and Sense of Place: On situational and phenomenological geographies. Electronic Working Paper 12. London School of Economics and Political Science, London: Media@Ise, 2007. 


\section{Time-Space and Body Routines}

Encounter

-Attentive contact

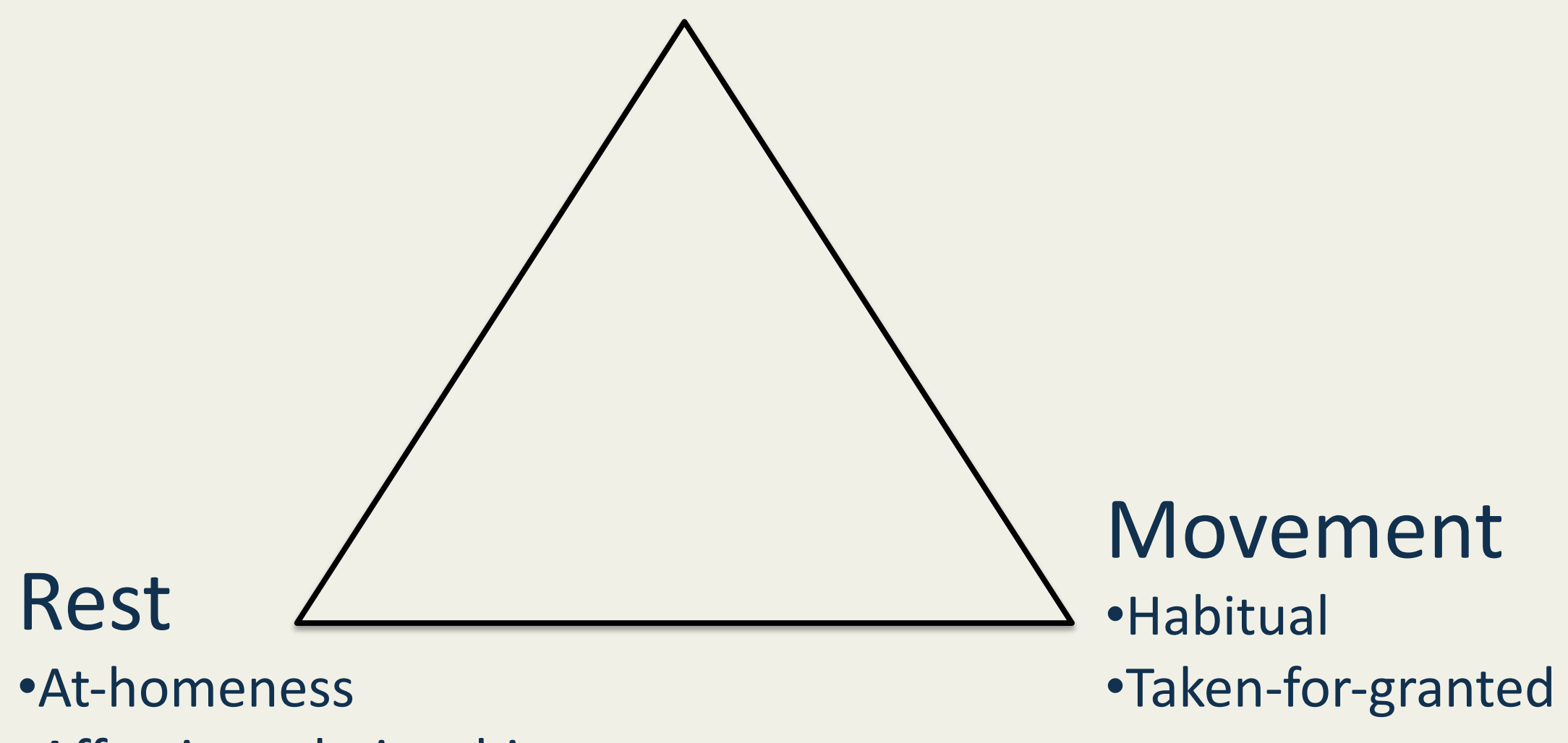

-Affective relationships 


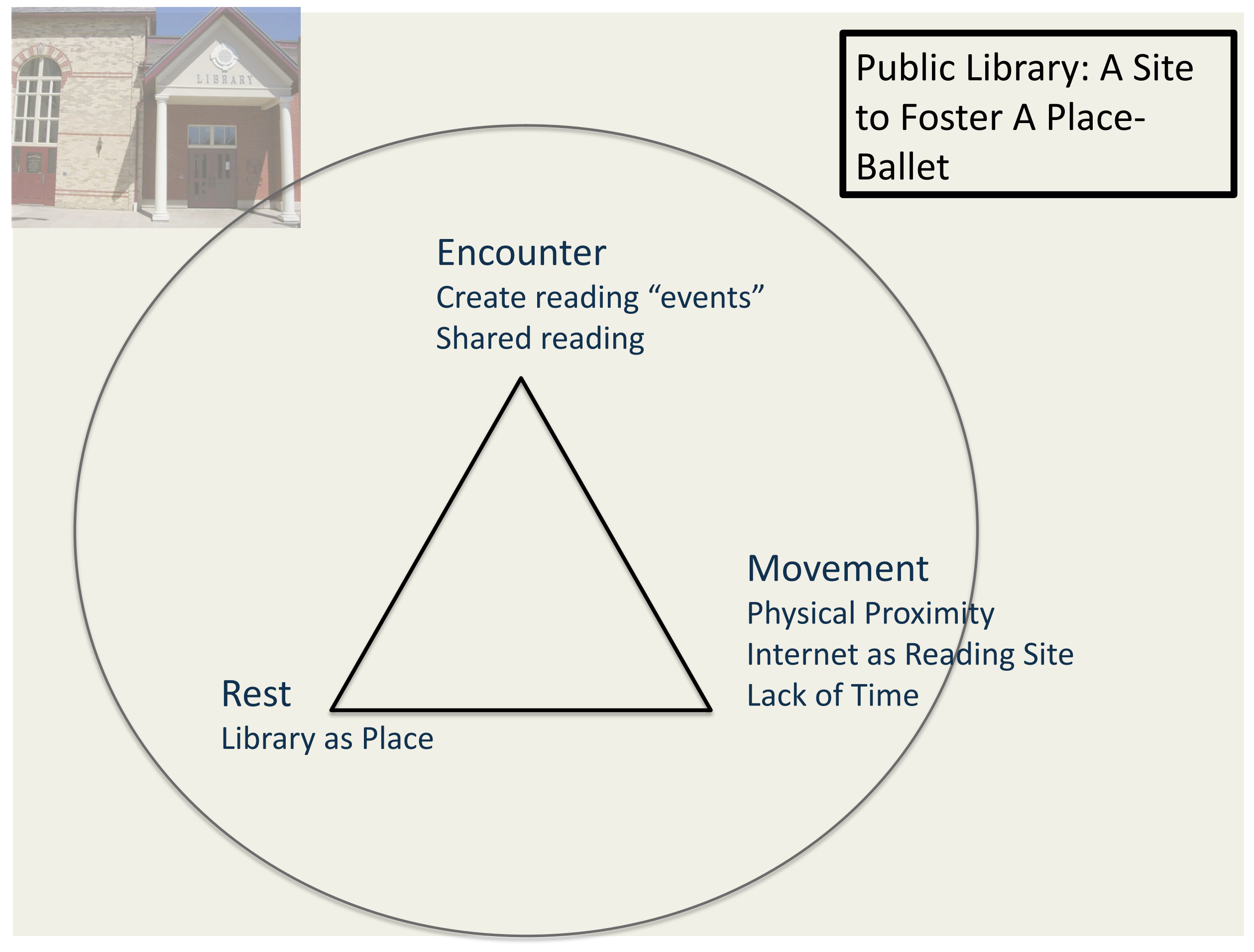




\section{Thanks}

Paulette Rothbauer

Faculty of Information \& Media Studies

prothba2@uwo.ca

This research was supported by a Standard Research Grant (2005-2008) from the Social Sciences and Humanities Research Council, \# 410-2005-033. 